\title{
ESTIMATION OF SURFACE DEFORMATION DUE TO PASNI EARTHQUAKE USING SAR INTERFEROMETRY
}

\author{
Muhammad Ali ${ }^{1}$, Muhammad Imran Shahzad ${ }^{1,2}$, Majid Nazeer ${ }^{1,2}$, Jameel Hussain Kazmi \\ ${ }^{(1)}$ Earth \& Atmospheric Remote Sensing Lab (EARL), COMSATS Institute of Information Technology, Islamabad, Pakistan - \\ muhammadali.geo1@gmail.com \\ ${ }^{(2)}$ Tenure Track Assistant Professor (Photogrammetry \& Remote Sensing), Department of Meteorology, COMSATS Institute of \\ Information Technology, Islamabad, Pakistan - imran.shahzad@ comsats.edu.pk \\ ${ }^{(3)}$ Department of Geography, University of Karachi, Pakistan.
}

KEY WORDS: InSAR, Surface Deformation, Sentinet-1 Earthquake, Pasni.

\begin{abstract}
:
Earthquake cause ground deformation in sedimented surface areas like Pasni and that is a hazard. Such earthquake induced ground displacements can seriously damage building structures. On 7 February 2017, an earthquake with 6.3 magnitudes strike near to Pasni. We have successfully distinguished widely spread ground displacements for the Pasni earthquake by using InSARbased analysis with Sentinel-1 satellite C-band data. The maps of surface displacement field resulting from the earthquake are generated. Sentinel-1 Wide Swath data acquired from 9 December 2016 to 28 February 2017 was used to generate displacement map. The interferogram revealed the area of deformation. The comparison map of interferometric vertical displacement in different time period was treated as an evidence of deformation caused by earthquake. Profile graphs of interferogram were created to estimate the vertical displacement range and trend. Pasni lies in strong earthquake magnitude effected area. The major surface deformation areas are divided into different zones based on significance of deformation. The average displacement in Pasni is estimated about 250-mm. Maximum pasni area is uplifted by earthquake and maximum uplifting occurs was about 1200$\mathrm{mm}$. Some of areas was subsidized like the areas near to shoreline and maximum subsidence was estimated about 1500-mm. Pasni is facing many problems due to increasing sea water intrusion under prevailing climatic change where land deformation due to a strong earthquake can augment its vulnerability.
\end{abstract}

\section{INTRODUCTION}

Land subsidence in coastal areas due to seismic activity can result in sea water intrusion. Without proper disaster management mechanisms the earthquake can cause a lot of damage to the coastal areas of developing countries. Therefore, this study focuses on estimation of land subsidence deformation in coastal area due to seismic activity which is a challenging task through traditional methods. However, InSAR has become powerful solution to monitor deformation of the Earth's surface. A single InSAR observation can measure displacements only along the radar line-of-sight (Bürgmann, Rosen, \& Fielding, 2000).

SAR satellite detects obliquely descendent not directly below. It is in ascending orbit (northward) that the satellite detects from west and it is in descending orbit (southward) that the satellite detects from east. In earth rotation when the ground moves westward, if satellite detects in ascending orbit (northward), the ground transfers close to the satellite. By distinction, if satellite observes in descending orbit (southward), the ground seems far from the satellite (Japan, 2010).

Particularly in the last 10 years, the enriched availability of new SAR tools and satellite collections has encouraged a solid development of processing procedures. Depth accuracies able to find the small ground deformation signals are linked to the different phases of the seismic cycle (Salvia et al., 2012).
Synthetic aperture radar interferometry (InSAR) from space has become powerful tools to monitor deformation of the Earth's surface. A single InSAR observation densely measures displacements only along the radar line-of-sight (LOS) direction (Hudnut et al., 1996). The replicated deformation field from the model effortlessly concurs with the result derived from the SAR interferometric measurement (Xia, 2005).

When it is used to estimate surface deformation caused by an earthquake, the geological process of how the earthquake happened can be set up by assessing the activity of the underground faults from the spreading of ground surface displacement, and InSAR could be used for earthquake predicting in the future(Japan, 2010).

Pakistan is located in a seismically active region at a juncture of the Indian and the Eurasian tectonic plates that strike in the area, which repeatedly leaves its inhabitants at the targets of deadly earthquakes (PMD \& NORSAR, 2007) (USGS, 2015). Therefore, existence of elevated beaches and marine terraces beside the Makran coast specifies periodic uplift of the continental margin causing from large-magnitude earthquakes. The uplift resulting from the November 28, 1945 (M 8.3) earthquake at Pasni and Ormara, Pakistan (Page, Alt, Cluff, \& Plafker, 1979).

The Owen Fault Zone is a alter fault in the Arabian Sea that is linked with a tectonic margin. It extends from the Gulf of Aden in a northeast track to the Makran coast where it go in the Balochistan region. Then it carry on as a land fault known as the Chaman Fault along Pakistan's western boundary with Afghanistan. It 
initiates near Kalat, in the northern Makran range, passes near Quetta and carry on to Kabul, Afghanistan. Both the Owen Fault Zone and the Chaman Fault Zone can create large harsh earthquakes. The great Quetta earthquake of 1935 occurred along the Chaman Fault. Other major thrust zones exist along the Kirthar, Sulaiman and Salt mountain ranges of Pakistan (Pararas-Carayannis, 2005a).

Recently, on $7^{\text {th }}$ February 2017, another earthquake with 6.3 magnitudes occurred along the coast of Pasni, Balochistan, Pakistan (fig. 1). The quake hit at 03:04 am (local time), with the epicenter $23-\mathrm{km}$ southwest of the coastal town of Pasni at a depth of 25-km (USGS, 2017). The epicenter of the earthquake was 90 kilometers south of the town of Turbat which is just off the coast and the depth was just below the seabed (PMD, 2017).

Off the south coast of Pakistan and southeast coast of Iran, the Makran trench is the existing surface appearance of active subduction of the Arabian plate underneath the continental Eurasian plate, which converges at a rate of approximately $20 \mathrm{~mm} / \mathrm{yr}$. While the Makran subduction zone has a quite slow convergence rate, it has created huge devastating earthquakes and tsunamis. For example, the November 27, 1945 M8.0 mega-thrust earthquake produced a tsunami within the Gulf of Oman and Arabian Sea, killing over 4,000 people (USGS, 2017).

\section{Study Area}

Pasni is located on Makran coast on Arabian Sea and almost $450 \mathrm{~km}$ away from Karachi. It is a medium size town and a fishing port in Gwadar District, Balochistan with population around 33,000 (Places, 2016).

The topography of the study area is low jagged hills of the Makran coast range (fig. 1). The flat land is more collective on the way to the coast. The unspoilt and pristine beaches of Pasni deal some of the most fascinating sceneries along the Arabian Sea. Shadi Kaur (river) served by attached rain water streams, drains into the Arabian Sea just north of the town. Vegetation is mostly of hardy desert shrubs. The town houses a modern fish harbor and Port of Pasni, with fishing being the main profession of the local residents. Cold catch is also sent to Turbat and Karachi for sale in the larger markets (Hughes-Buller \& Rai, 2007).

The town houses a modern fish harbor and Port of Pasni, with fishing being the main occupation of the town dwellers. Pasni Airport is shared by Pakistan Air Force (PAF), Pakistan Navy and civil aviation. PAF as well as PN-Aviation operational facilities are housed nearby. Daily commercial flights link the town with Karachi. In 2008, the government approved the construction of Shadi Kaur storage dam near Pasni, which is expected to alleviate some of the power deficiency of the region (Times, 2008).

Pasni is a town situated at the middle of the Makran coast, a town of fishermen where almost $80 \%$ residents are connected with fisheries in one way or the other. These people produce their cash from the 780-kilometer belt of sea, often called 'Bahr-e-Baloch' (The Baloch Sea). On April 3, 1989 the then Prime Minister Benazir Bhutto inaugurated Pasni Fish Harbor, built at an authorized price of 560 million rupees (Nation, 2013).

Unhappily, this was all short-term. Due to the daydreaming of the consecutive governments and division stupidity, active scouring of the harbor was mistreated. The unavoidable outcome was the support up of sediments in the harbor which eventually stopped it, so much so that it closed all the waterways of the harbor and arrival boats and launches at Pasni harbor became impossible. The Harbor essentially became ineffectual (Latif, 2015).

Balochistan is a high risk zone for crucial disasters, with drought, earthquake and tsunami. According to scientists, after an interval since the 1935 earthquake, the province looked to be stimulating for another major earthquake. The whole province was in a seismically active region (DAWN, 2008). In situation of a tsunami produced by an earthquake beside Makran, the areas of Ormara, Pasni and Sonmiani would be in most risk (Mahmood, Khan, Rafi, \& Løvholt, 2012).

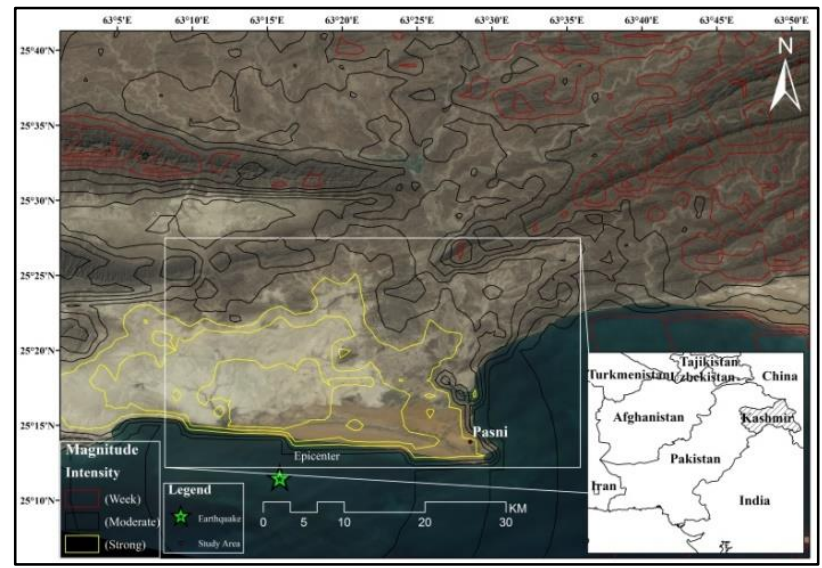

Figure 1. Natural color image showing the study area located in Makran coast and rectangular box identifying the area under processing. Contour lines with different colors showing the intensity of earthquake.

Pasni town, like the rest of Makran Coast, is affected by a seismic fault line (Makran Accretionary Front) caused by the northward movement $(40-50 \mathrm{~mm} /$ year $)$ of the Arabian Plate against the Eurasian Plate. Tectonic activity emanating from this subduction zone in the Arabian Sea causes occasional, low intensity earthquakes (Pararas-Carayannis, 2005b).

\section{DATA SET}

Near global coverage and in all weather conditions including day and night make SAR data good for remote sensing analysis and natural hazards monitoring. In this study, Sentinel-1 Wide Swath data is used (Table 1), because of its considerable coverage area and high spatial resolution. Existing archive of previous acquisitions allows selection of pairs of pre- and post-event images with suitable baselines (distance separating the two orbits of a pair of images) and time interval. For estimation of 
surface deformation caused by earthquake using SAR imagery, two techniques exist: Interferometric SAR (InSAR) (Rosen et al., 2000), and sub-pixel image decorrelation. For the Pasni earthquake, Interferometric SAR (InSAR), the most useful technique, can only give reliability in measurement on some areas where temporal decorrelation and decorrelation due to the large earthquake deformation itself are less severe. (Michel, R., Avouac, \& Taboury, 1999).

Table 1. Sentinel-1 Wide Swath SAR Satellite data used for this study

\begin{tabular}{ccccc} 
No & Orbit & Track & Date & UTC Time \\
\hline & & & & \\
1 & 14296 & Descending & $09-12-2016$ & $01: 42$ \\
2 & 14646 & Descending & $02-01-2017$ & $01: 42$ \\
& & & & \\
3 & 14996 & Descending & $26-01-2017$ & $01: 42$ \\
4 & 15135 & Ascending & $04-02-2017$ & $13: 51$ \\
& & & & \\
5 & 15310 & Ascending & $16-02-2017$ & $13: 51$ \\
& & & & \\
6 & 15485 & Ascending & $28-02-2017$ & $13: 51$ \\
\hline
\end{tabular}

\subsection{Selection of Data Pairs Appropriate for SAR Interferometry}

For the selection of appropriate data pairs for SAR Interferometry, it is important to calculate base length values. Different methods are available for the calculation of base line (Aydöner, D.Maktav, \& Alparslana, 1999; Small, Werner, \& Nuesch, 1993). The data with less than $600 \mathrm{~m}$ base length is good for SAR interferometry (Gens, R, \& Genderen, 1996).

\section{METHODOLOGY}

One of the most important remote sensing recognizable measured or estimated from Earth observation (EO) data is crustal deformation. The InSAR technique can calculate the projection of the deformation vector onto the Line of Sight (LOS) direction, defined as the shortest path from a certain point on ground to the SAR antenna phase center. Initially, it can provide surface deformation maps with high spatial resolutions $(5-80 \mathrm{~m})$ over large areas. Then, InSAR is mostly sensitive to vertical displacements and finally, it is a remote-sensing technique and as such it does not need field work and can be accessible almost worldwide (Tolomei, Salvi, Boncori, \& Pezzo, 2014).

The small spatial baseline (i.e. orbital separation) between the two Sentinel-1A SAR acquisitions is accepted for the interferometric pair by a perpendicular element as small as $0.8 \mathrm{~m}$, which is gainful for the deformation measurement due to very little topographic contribution and geometric decorrelation for InSAR data processing. The geometric configuration of small baseline length specifies that the Sentinel-1A SAR images was selected with a good orbital overlap during the revisit period (Yang et al., 2017).

To remove topographic fringes, Shuttle Radar Topographic Mission (SRTM) Digital Elevation Model (DEM) data was used (Yang et al., 2017). The SRTM data were processed using SNAP software. To simply identify the fringe patterns specifically to conduct a phase unwrapping more certainly, we applied filtering operations (Baran, Stewart, Kampes, Perski, \& Lilly, 2003).

Additionally, to decrease the phase noise and increase the quality of interferogram, a phase filter was used to process the interferogram. Snaphu software developed by Chen and Zebker at Stanford University was utilized to unwrap differential interferogram (Chen \& Zebker, 2002).

Phase Unwrapping is a technique which was applied for this study. An interferogram image consists of phase information dependent upon the terrain topography. This phase information is given modulus $2 \pi$, the integer coefficients of $2 \pi$ needs to be calculated to determine the ambiguity, which is called, phase unwrapping. There are a number of methods invented for phase unwrapping (Aydöner et al., 1999).

Conversion of unwrapped phases in displacement $(\mathrm{mm})$ values, preferentially in vertical instead line-of-sight (LOS) direction is estimated by the following formula.

$$
\text { Vertical Displacement }=\frac{\emptyset_{\text {unw }} * \lambda}{-4 \pi * \cos \theta_{\text {inc }}}
$$

Equation 1. Showing formula for conversion of phase difference into Where, vertical displacement cause by the earthquake.

$\lambda=56 \mathrm{~mm}, \pi=3.14$ (Zan \& Guarnieri, 2006).

Displacement values calculated in millimeters ( $\mathrm{mm})$.

\section{RESULTS AND DISCUSSION}

Using SAR data a synoptic view of the surface displacement covering the whole area of Pasni earthquake has been obtained. With 6 Sentinel-1 Wide Swath images over 9-Dec-2016 to 28-Feb-2017, the SAR interferometric technique is used to estimate vertical displacement due to earthquake over study area. This section aims to present and analyze the results which obtained with InSAR technique. 
The International Archives of the Photogrammetry, Remote Sensing and Spatial Information Sciences, Volume XLII-3, 2018 ISPRS TC III Mid-term Symposium "Developments, Technologies and Applications in Remote Sensing”, 7-10 May, Beijing, China 


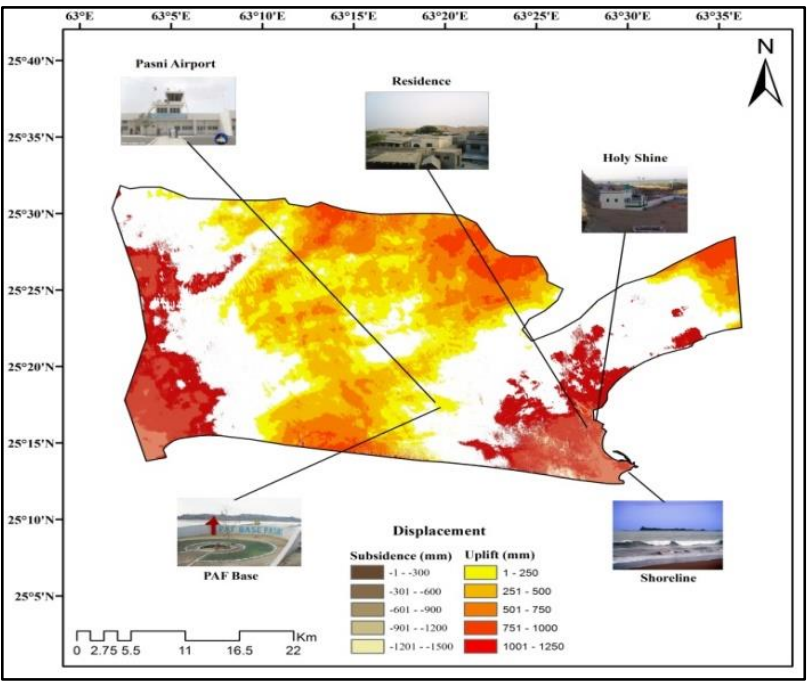

Figure 4. Map showing the major affected areas due to vertical displacement caused by the earthquake in Pasni, Balochistan.

On 7 February 2017, an earthquake with 6.3 magnitudes occurred in Pasni, Balochistan, Pakistan. The earthquake hit at 03:04 am (local time), with the epicenter 23-km southwest of the coastal town of Pasni at a depth of 25$\mathrm{km}$ (USGS, 2017). Pasni lies in strong earthquake magnitude zone. Due to the earthquake whole Pasni area was affected and surface was also faced deformation. Fig. 7 shows the major and important topography of pasni which is affected by earthquake.

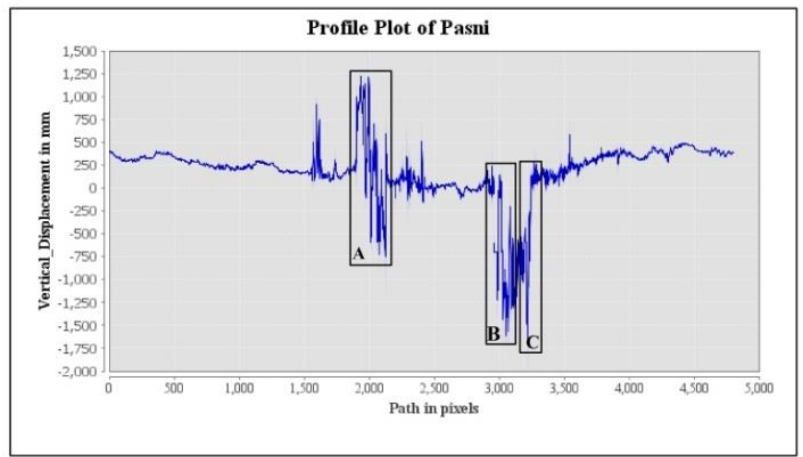

Figure 5. Profile graph of the vertical displacement in pasni, also indicating maximum deformation (uplifting and subsidence) in selected zones (A, B \& C) of study area.

To analyze deeply about surface deformation we select three zones (A, B and C) which were highly affected by earthquake and showing maximum deformation. These areas are marked on map and also on profile graph.

The given facts \& figures and results shows that average uplifting about 250-mm (millimeters) was appeared in pasni. The uplifting near the coastal area is small or showing subsidence (zone C). There are two possible reasons for that. First, Coastal area is covered by medium to fine grained sand, due to water effects (tides) the coastal area was wet and when earthquake occurs surface subsided. Second reason the surface geology. When we move away from the coast the uplifting is increased. According to the given result (fig. 8), area (Zone B and C) in the middle of the Pasni and coastal area shows maximum subsidence about $1500-\mathrm{mm}$. Both areas are covered by sand; medium to fine grained. The area (Zone A) shows the maximum uplifting approximately $1200-\mathrm{mm}$. this area covered by Unconsolidated sand, pebbles, gravel and clayey material and some parts covered by fine sand, silt and clayed material.

\subsection{Surface Deformation and Buildup area}

Pasni is a medium-sized city and a fishing port in Gwadar District, Balochistan, Pakistan. Its population is around 33,000. It is located on the Makran coast on Arabian Sea about $450 \mathrm{~km}$ from Karachi (Places, 2016). As it is shown in fig. 9 that pasni buildup area is near to coast. So with the occurrence of earthquake the coastal area was subsidized. Pasni is also facing many problems due to increasing sea water intrusion under prevailing climatic change where land deformation especially subsidence due to a strong earthquake can augment its vulnerability.

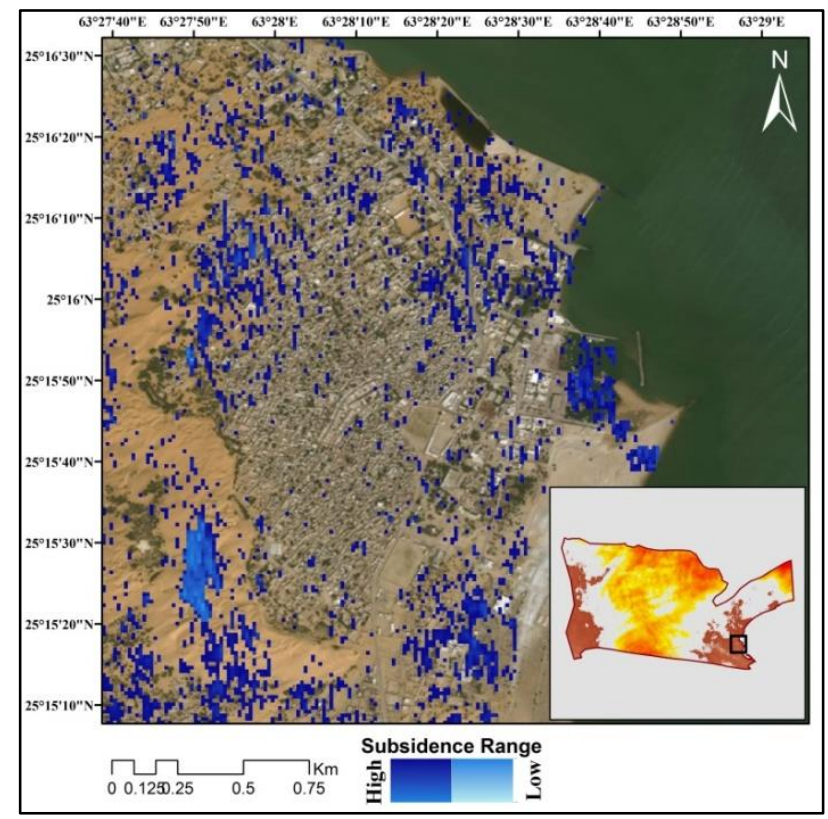

Figure 6. Surface subsidence range in buildup area of pasni due to earthquake.

\section{SUMMARY AND CONCLUSIONS}

Earthquake cause surface deformation in sediments surface areas like pasni. Maximum area of Pasni is covered by the thick bedded mud stone with thin bedded fine grained sandstone and sand fine, silt and clayed material. On 7 February 2017 earthquake (6.3 magnitude) hits pasni. Sentinel-1 (Wide Swath) satellite C-band data can successfully estimate surface deformation. The presently available InSAR data can estimate deformation with period of 12 days. As regards the data accessibility, in 2014 a new InSAR period has 
started, with the successful placement of the European Sentinel-1 SAR satellite, able to make available SAR images for maximum seismic areas of the world with constant repeat pass, for many years in the future. The better SAR data accessibility, the larger coverage, the constant temporal sampling provided by the Sentinel-1 sensors will generate a strong increase in the observation of crustal deformation worldwide, providing new high quality data for developing and testing models of the earthquake. Sentinel-1 Wide Swath Interferometry was used for the 7 February 2017 Pasni earthquake area. The obtained results are conceptually summarized in the above maps and graphs. The following conclusions were calculated from the analysis.

I. Surface displacement field for earthquake measured an average of $250-\mathrm{mm}$ of range displacement in the interferogram.

II. Major displacement areas marked as zones (A, B and $\mathrm{C}$ ) in the pasni displacement map.

III. With the earthquake maximum pasni area was uplifted and major coastal area subsidized (Zone B and C).

IV. Pasni lies in the strong earthquake magnitude zone and facing disaster affects.

V. Due to the surface geology of the Pasni some areas subsided and some areas are uplifted by the earthquake.

VI. Pointed areas (zone A, B \& C) of Pasni revealed major deformation affects, surface subsided maximum about $1500-\mathrm{mm}$ in Zone B \& C and uplifted maximum about $1200-\mathrm{mm}$ in Zone A.

\section{REFERENCES}

Aydöner, C., D.Maktav, \& Alparslana, E. (1999). Ground deformation mapping using InSAR. XXth ISPRS (International Society for photogrammetry and Remote Sensing) Congress, 12-23.

Baran, I., Stewart, M.P., Kampes, B.M., Perski, Z., \& Lilly, P. (2003). A modification to the Goldstein radar interferogram filter. IEEE Transactions on Geoscience and Remote Sensing, 41(9), 21142118.

Bürgmann, Roland, Rosen, Paul A., \& Fielding, Eric J. (2000). Synthetic Aperture Radar Interferometry to Measure Earth's Surface Topography and Its Deformation. Annual Review of Earth and Planetary Sciences, 28, 169-209.

Chen, CW (Chen, CW), \& Zebker, HA (Zebker, HA). (2002). Phase unwrapping for large SAR interferograms: Statistical segmentation and generalized network models. IEEE TRANSACTIONS ON GEOSCIENCE AND REMOTE SENSING, 40(8), 1709-1719.

DAWN. (2008). Balochistan crying out for disaster strategy: $\quad$ experts. from https://www.dawn.com/news/324758
Gens, R, \& Genderen, Van. (1996). Sar interferometry-issues, techniques, applications. International Journal for Remote Sensing, 17(10), 1803-1835.

Hudnut, K. W., Shen, Z., Murray, M., McClusky, S., King, R., Herring, T., . . . Bock, Y. (1996). CoSeismic Displacements of the 1994 Northridge, California, Earthquake. Bulletin of the Seismological Society of America, 86, S19-S36.

Hughes-Buller, \& Rai, J. (2007). Baluchistan District Gazetteer Series: printed at Bombay Education Society's Press.

Japan, Geospatial Information Authority of. (2010). Monitoring the Earth Deformation from Space. from

http://vldb.gsi.go.jp/sokuchi/sar/mechanism/inte rpretation-e.html

Latif, Salman. (2015). BALOCHISTAN: FISHERMEN PEG HOPES ON RESTORATION OF PASNI HARBOR.

Mahmood, Nasir, Khan, Karam, Rafi, Zahid, \& Løvholt, Dr. Finn. (2012). Mapping of Tsunami Hazard along Makran Coast of Pakistan. Norges Geotekniske institutt.

Michel, R., Avouac, J.-P, \& Taboury, J. (1999). Measuring ground displacements from SAR amplitude images: Application to the Landers earthquake,. Geophys. Res. Lett., 26(7), 875-878.

Nation, The. (2013). Resolution adopted for 'Baloch Sea'. Quetta: Retrieved from http://nation.com.pk/national/08-Oct2013/resolution-adopted-for-baloch-sea.

Page, William D, Alt, John N., Cluff, Lloyd S., \& Plafker, George. (1979). Evidence for occurence of large magnitude earthquakes along the Makran coast of Iran and Pakistan. Tectonophysics, 52(1), 533-547.

Pararas-Carayannis, George. (2005a). Earthquake and Tsunami of 28 November 1945 in Southern Pakistan.

Pararas-Carayannis, George. (2005b). Earthquake and Tsunami of 28 November 1945 in Southern Pakistan. 2005, from http://www.drgeorgepc.com/Tsunami1945Pakist an.html

Places, Pakistan Travel. (2016). Pasni Beach, Balochistan. 2016, from http://pakistantravelplaces.com/destination/pasn i-beach-balochistan/

PMD. (2017). Powerful earthquake jolts Balochistan coast. from https://tribune.com.pk/story/1320178/powerfulearthquake-jolts-balochistan-coast/

PMD, \& NORSAR. (2007). Seismic Hazard Analysis and Zonation for Pakistan, Azad Jammu and Kashmir.

Rosen, P. A., Hensley, S., Joughin, I. R., Li, F. K., Madsen, S. N., Rodriguez, E., \& Goldstein, R. M. (2000). Synthetic aperture radar interferometry. Proc. IEEE, 88(3), 333-382. 
Salvia, S., Stramondoa, S., Funningb, G.J., Ferrettic, A., Sartid, F., \& Mouratidisd, A. (2012). The Sentinel-1 mission for the improvement of the scientific understanding and the operational monitoring of the seismic cycle. Remote Sensing of Environment, 120, 164-174.

Small, D., Werner, C., \& Nuesch, D. (1993). Baseline modelling for ERS-1 SAR interferometry. IEEE, $18-21$.

Times, Daily. (2008). PC to initiate construction of two dams in Balochistan. from http://www.dailytimes.com.pk/default.asp?page $=2008 \% 5$ C $04 \% 5$ C $20 \% 5$ Cstory 20-4$2008 \_$pg $5 \quad 7$

Tolomei, C., Salvi, S., Boncori, J.P. Merryman, \& Pezzo, G. (2014). InSAR measurement of crustal deformation transients during the earthquake preparation processes: a review. Bollettino di Geofisica Teorica ed Applicata, 56(2), 151-166.

UPSeis. (2007). The effects of Earthquake. from http://www.geo.mtu.edu/UPSeis/hazards.html

USGS. (2015). Pakistan in the most active quake zone. from https://www.dawn.com/news/1215636

USGS. (2017). M 6.3 - 22km WSW of Pasni, Pakistan. from https://earthquake.usgs.gov/earthquakes/eventpa ge/us20008ic7\#executive

Xia, Ye. (2005). Bam earthquake: Surface deformation measurement using radar interferometry. Acta Seismologica Sinica, 18(4), 451-459. doi: 10.1007/s11589-005-0023-y

Yang, Yinghui, Chen, Qiang, Xu, Qian, Zhang, Yijun, Yong, Qi, \& Liu, Guoxiang. (2017). Coseismic surface deformation of the 2014 Napa earthquake mapped by Sentinel-1A SAR and accuracy assessment with COSMO-SkyMed and GPS data as cross validation. International Journal of Digital Earth, 1-17.

Zaidi, Syed Mukhtar Abbas, \& Muhammad, Ali. (2016). GEOLOGICAL MAP OF PASNI \& JABAL ZARAIN QUADRANGLES, GWADAR DISTRICT, BALOCHISTAN, PAKISTAN. GEOLOGICAL SURVEY OF PAKISTAN.

Zan, F. De, \& Guarnieri, A.M. Monti. (2006). TOPSAR: Terrain Observation by Progressive Scans. IEEE Transactions on Geoscience and Remote Sensing 44(9), 2352-2360. 